\title{
Effects of microwave radiation on brain energy metabolism and related mechanisms
}

\author{
Yan-Hui Hao, Li Zhao* and Rui-Yun Peng*
}

\begin{abstract}
With the rapid development of electronic technologies, anxiety regarding the potential health hazards induced by microwave radiation (MW) has been growing in recent years. The brain is one of the most sensitive target organs for microwave radiation, where mitochondrial injury occurs earlier and more severely than in other organs. Energy metabolism disorders do play an important role during the process of microwave radiation-induced brain damage. In this paper, we will review the biological effects of microwave radiation, the features of brain energy supply and consumption and the effects of microwave radiation on mitochondrial energy metabolism and potential related mechanisms.
\end{abstract}

Keywords: Microwave radiation, Brain, Energy metabolism, Mitochondria, Mechanisms

\section{Introduction}

Microwaves (MW), electromagnetic waves with frequencies ranging from $300 \mathrm{MHz}$ to $300 \mathrm{GHz}$, have been widely used in the telecommunications, agriculture, transportation, medical and military fields. The popularization of mobile phones, computers, household appliances and other electronic equipment has made learning, working and accessing entertainment much more convenient. With the intensive development of various advanced military weaponry equipment, such as early warning aircraft, electronic jammers and new radar, soldiers are always exposed to intricate environmental factors, including intensive and complex MW radiation. As the fourth largest source of pollution after air, water and noise, MW radiation induces many biological effects [1]. The brain is the most sensitive target organ for MW radiation, where mitochondrial injury occurs earlier and more severely than in other organs. Studies on the effects of MW radiation on brain energy metabolism have aroused great concern.

\section{Review}

\section{Biological effects of MW radiation}

The biological effects of MW radiation fall into two types: thermal and non-thermal effects $[2,3]$. Both are present, with thermal effects prominent in the case of high-power and high-frequency MW radiation and non-

\footnotetext{
* Correspondence: lillyliz@163.com; ruiyunpeng18@126.com
}

Beijing Institute of Radiation Medicine, Beijing 100850, China thermal effects predominant in the case of low-power MW radiation [4]. MW radiation has multi-faceted effects on many systems within an organism, including the nervous [5-7], endocrine [8], cardiovascular [9], immune $[10,11]$, reproductive [12-14] and hematopoietic [15] systems. The brain always requires a high rate of oxygen and energy consumption to maintain regular functions. Therefore, this organ is sensitive to non-infectious stimuli such as ionizing radiation and hypoxia $[16,17]$. Research from our group and from others has demonstrated that microwave radiation damages hippocampal structures in rats, impairs long-term potentiation, decreases neurotransmitter concentrations, reduces synaptic vesicles in number and results in memory impairment $[5,18,19]$. Thus, the brain is generally accepted as the most sensitive target organ for MW radiation.

The damaging effects of MW radiation on the brain include brain dysfunction and brain structural damage. An epidemiological survey found that MW radiation caused human fatigue, headache, excitement, dreams, memory loss and other symptoms of neurasthenia [20]. In addition, there were impaired learning and memory abilities in rats after MW radiation, as determined by the Morris water maze $[5,6,21,22]$. MW radiation may also lead to neuronal shrinkage, nuclear condensation, mitochondrial swelling, an expanded endoplasmic reticulum, alterations to the synaptic gaps and widened vascular 
endothelial connections, where mitochondrial injury occurred earlier and more severely [5,21,23-25].

\section{Features of brain energy metabolism}

In the human body, the brain has the greatest demand for oxygen and is susceptible to disturbances in energy metabolism, which is determined by its high metabolic rate, high oxygen consumption and low energy reserves. Mitochondria are the key sites of oxidative phosphorylation (OXPHOS) and the synthesis of adenosine triphosphate (ATP). The redox enzymes and the coenzymes involved in the respiratory chain lie in the mitochondrial inner membrane in close proximity. Electrons passing through the respiratory chain drive protons from the matrix side to the cytoplasmic side across the mitochondrial inner membrane. When protons reflux along the concentration gradient, the energy released is used by ATP synthase to catalyze ATP synthesis.

In addition to energy conversion, mitochondria also play other important roles, such as in the regulation of apoptosis and $\mathrm{Ca}^{2+}$ storage. Mitochondria are not only the starting point of many signal transduction pathways but also the target.

\section{Effects of MW radiation on mitochondrial energy metabolism}

MW radiation is detrimental to brain energy metabolism. Intrinsically, neurons are extremely sensitive to a reduced ATP availability. As the main source of energy, mitochondria are prone to MW radiation-induced injury. Wang et al. [26] exposed monkeys to MW radiation with average power densities of $5 \mathrm{~mW} / \mathrm{cm}^{2}$ and $11 \mathrm{~mW} / \mathrm{cm}^{2}$ for $10 \mathrm{~s}$ and $4.68 \mu \mathrm{W} / \mathrm{cm}^{2}$ for $12 \mathrm{~h} / \mathrm{d}$ for $30 \mathrm{~d}$ cumulatively. Abnormalities in mitochondrial function-related metabolites in urine, such as succinic acid, citric acid and 2-keto-glutaric acid, were induced after a single radiation event of $5 \mathrm{~mW} /$ $\mathrm{cm}^{2}$ and $11 \mathrm{~mW} / \mathrm{cm}^{2}$ and after a long-term radiation of $4.68 \mu \mathrm{W} / \mathrm{cm}^{2}$, revealing by metabolomics the hypersensitivity of mitochondria to MW radiation.

\section{Effects of MW radiation on mitochondrial structure}

MW radiation leads to mitochondrial structural damage, primarily observed as mitochondrial swelling and cavitation and disorganized, broken and sparse cristae.

To some extent, MW radiation affects mitochondria structurally in a dose-dependent manner. Zhao et al. [5] exposed male Wistar rats to MW radiation with average power densities of $2.5,5$ and $10 \mathrm{~mW} / \mathrm{cm}^{2}$, with the specific absorption rates (SAR) of $1.05,2.1$ and $4.2 \mathrm{~W} / \mathrm{kg}$, respectively, for $6 \mathrm{~min} / \mathrm{d}$ for $30 \mathrm{~d}$. In the hippocampus of the MW-exposed rats, the mitochondria were swollen and vacuolized, and the cristae were disordered and fewer in number. In addition, these ultrastructural changes in the mitochondria tended to be more severe relative to the increasing SAR. Xie et al. [27] exposed male Wistar rats to $\mathrm{MW}$ radiation for $1 \mathrm{~h}$ at average power densities of 3 and $30 \mathrm{~mW} / \mathrm{cm}^{2}$, respectively. No significant changes occurred in the mitochondria of the hippocampus or cerebral cortex in the $3 \mathrm{~mW} / \mathrm{cm}^{2}$ group, while the mitochondria in the $30 \mathrm{~mW} / \mathrm{cm}^{2}$ group did become damaged. These results suggest that, within a certain range, the degree of mitochondrial structural damage positively correlates with the dose of MW radiation.

MW radiation damaging mitochondrial structures obeys a time-response relationship. Xie et al. [27] exposed male Wistar rats to $\mathrm{MW}$ radiation $\left(30 \mathrm{~mW} / \mathrm{cm}^{2}\right.$, duration: $1 \mathrm{~h}$ ). Immediately after radiation, the mitochondrial ultrastructure showed a slight disturbance in the rat hippocampus and cerebral cortex; $3 \mathrm{~h}$ after radiation, the visible swelling of the mitochondria increased significantly and cristae became disorganized, broken and sparse; $24 \mathrm{~h}$ after radiation, mitochondrial degeneration was observed, demonstrated by myelin-like structures and occasional dense deposits in the mitochondria. In short, ultrastructural changes in the rat brain mitochondria were induced within $24 \mathrm{~h}$ of the post-30 $\mathrm{mW} / \mathrm{cm}^{2} \mathrm{MW}$ radiation exposure.

Long-term and low-dose cumulative MW radiation leads to significant damage in mitochondria. Dong et al. [21] exposed SD rats to MW radiation $\left(4.68 \mu \mathrm{W} / \mathrm{cm}^{2}\right.$, $12 \mathrm{~h} / \mathrm{d}$, duration: $30 \mathrm{~d}$ ), which resulted in similar structural changes, such as swelling and cavitation in the mitochondria of the radiation-exposed rat hippocampus and cerebral cortex.

\section{Effects of MW radiation on mitochondrial energy metabolism \\ Reduced ATP content}

As the "cell power plant", the most important function of mitochondria is to provide energy for the cell; therefore, intracellular ATP content is one of the most direct and objective indicators in the evaluation of mitochondrial function. In addition, ATPases hydrolyze ATP to ADP and release the energy stored in ATP.

Certain doses of MW radiation cause reduction in mitochondrial ATP synthesis. Zhao et al. [25] exposed male Wistar rats to pulsed MW radiation $\left(30 \mathrm{~mW} / \mathrm{cm}^{2}\right.$, duration: $5 \mathrm{~min}$ ). The results showed that the content of mitochondrial ATP in the hippocampus of MWexposed rats dropped to the lowest levels $3 \mathrm{~d}$ after radiation and recovered $7 \mathrm{~d}$ after radiation, while the activity of the ATPases was greatly enhanced $3 \mathrm{~d}$ after radiation and recovered $7 \mathrm{~d}$ after radiation, suggesting a compensatory role played by this negative feedback regulation. Sander et al. [28] exposed SD rats to MW radiation with a frequency of $591 \mathrm{MHz}$ at an average power density of $13.8 \mathrm{~mW} / \mathrm{cm}^{2}$, which induced a reduced availability of ATP, resulting in brain energy metabolism disorders. 


\section{Decreased succinate dehydrogenase (SDH) activity}

As one of the key enzymes of mitochondrial energy metabolism, SDH binds to the mitochondrial inner membrane and catalyzes the dehydrogenation of succinate to generate ATP ultimately, forming a bridge between the Krebs cycle and OXPHOS.

$\mathrm{MW}$ radiation reduces the activity of SDH. Zhao et al. [25] exposed male Wistar rats to pulsed MW radiation (30 $\mathrm{mW} / \mathrm{cm}^{2}$, duration: $5 \mathrm{~min}$ ). The SDH activity of the MW-exposed rat hippocampus decreased significantly $6 \mathrm{~h}$ after radiation, resulting in abnormalities in mitochondrial energy metabolism. Wang et al. [29] exposed Wistar rats to high power microwave (HPM) radiation of 10,30 and $100 \mathrm{~mW} / \mathrm{cm}^{2}$ for $5 \mathrm{~min}$, respectively. They also found reduced SDH activity present in every exposure group, which recovered $7 \mathrm{~d}$ after radiation. Another study exposed male Wistar rats to MW radiation of $30 \mathrm{~mW} / \mathrm{cm}^{2}$ for $15 \mathrm{~min}$. The SDH activity of the MWexposed rat hippocampus did not change significantly at $14 \mathrm{~d}$ after radiation, indicating that the MW radiationinduced decline in SDH activity is reversible under certain conditions [23].

\section{Suppressed cytochrome c oxidase (COX) activity}

COX is embedded in the mitochondrial inner membrane and is the terminal complex of the mitochondrial electron transport chain. As another one of the key enzymes of mitochondrial energy metabolism, COX is the only enzyme to transport electrons to oxygen to produce $\mathrm{H}_{2} \mathrm{O}$ and ATP [30,31]. It is believed that $90 \%$ of intracellular molecular oxygen is utilized by COX [32].

Certain doses of MW radiation negatively impact the activity of COX. Wang et al. [33] exposed primary cultures of cerebral cortical neurons of Wistar rats to continuous MW radiation of $900 \mathrm{MHz}$, with SARs of 0.38 , $0.76,1.15,2.23$ and $3.22 \mathrm{~W} / \mathrm{kg}$, respectively, for $2 \mathrm{~h} / \mathrm{d}$ for 4 to $6 \mathrm{~d}$. The results showed that the toxic effects of MW radiation on COX activity accumulated and that there was a dose-dependent relationship. Xiong et al. [34] used MW radiation of $30 \mathrm{~mW} / \mathrm{cm}^{2}$ to irradiate male Wistar rats. The decreased COX activity and the reduced expression of COX I/IV mRNA and COX I protein were found after MW radiation, illustrating that MW radiation impacted COX activity at multiple levels.

\section{Potential mechanisms involved in MW radiation-induced disturbances in mitochondrial energy metabolism}

By the rapid development of modern molecular biology techniques, studies on the mechanisms of the biological effects of MW radiation have been possible at the cellular and molecular levels. This section will review the potential mechanisms of MW radiation-induced brain energy metabolism disorders from seven aspects, including gene expression, the mitochondrial membrane, apoptosis, oxidative stress (OS), $\mathrm{Ca}^{2+}$ overload, mitochondrial DNA and the involved signal transduction pathways.

\section{Altered gene expression in the respiratory chain}

MW radiation causes abnormal expression of the genes encoding the respiratory chain, resulting in brain energy metabolism disorders. Zhao et al. [35] exposed male Wistar rats to pulsed $\mathrm{MW}$ radiation $\left(30 \mathrm{~mW} / \mathrm{cm}^{2}\right.$, duration: $5 \mathrm{~min}$ ). There were multiple genes differentially expressed $6 \mathrm{~h}$ after radiation in the rat hippocampus (upregulated: syn1, ptprj, CD74 and MHCII; downregulated: ttr, enpp2, folr1, cdh22, spata2, spp1, calb2, tacl and dnpi), some of which (syn1, ttr and enpp2) are closely related to the metabolic function of mitochondria. As the neural metabolic marker, COX contains 13 subunits, with COX I-III encoded by mitochondrial genes and the other 10 subunits encoded by nuclear genes. COX I constitutes the catalytic center, and COX IV regulates the enzyme activity responding to ATP/ ADP content [36,37]. Zhao et al. [38] found that exposing male Wistar rats to pulsed $\mathrm{MW}$ radiation $\left(30 \mathrm{~mW} / \mathrm{cm}^{2}\right.$, duration: $5 \mathrm{~min}$ ) reduced the expression of $\mathrm{COX} \mathrm{I/II}$ mRNA $6 \mathrm{~h}$ after radiation and increased the expression of COX IV mRNA in $1 \mathrm{~d}$, both of which tended to recover in 3 to $7 \mathrm{~d}$, demonstrating that reduced COX activity in the rat hippocampus occurred after MW radiation of $30 \mathrm{~mW} /$ $\mathrm{cm}^{2}$. Xie et al. [39] exposed rats to acute MW radiation for $1 \mathrm{~h}$ at average power densities of $3 \mathrm{~mW} / \mathrm{cm}^{2}$ or $30 \mathrm{~mW} / \mathrm{cm}^{2}$, respectively. After MW radiation of $3 \mathrm{~mW} /$ $\mathrm{cm}^{2}$ for 0,3 and $24 \mathrm{~h}$, no significant changes in the COX I and COX IV mRNA expression levels in the rat cerebral cortex and hippocampus were found. However, after MW radiation of $30 \mathrm{~mW} / \mathrm{cm}^{2}$ for 0,3 and $24 \mathrm{~h}$, COX I mRNA expression in the rat cerebral cortex and hippocampus decreased significantly, but no significant change in COX IV mRNA expression levels was found. In conclusion, MW radiation downregulates the COX I gene encoded by mitochondrial DNA in the cerebral cortex and hippocampus of rats in a dose-dependent manner. These results suggest that the changes in gene expression caused by MW radiation are important factors in mitochondrial dysfunction and brain energy failure.

\section{Damaged mitochondrial membrane}

The mitochondrial membrane enables the mitochondria to be relatively independent and to maintain homeostasis its internal environment and plays important roles in energy conversion, signal transduction and material transport. A variety of enzymes closely related to energy metabolism, such as SDH and complex I-IV, bind to the mitochondrial membrane. As a key part of the synthesis of ATP, a damaged mitochondrial membrane leads to a decreased activity of complex I/III and to further disturbances in energy metabolism [40]. 
The structural damage of the mitochondrial membrane is one of the most important mechanisms of MW radiation-induced disturbance of brain energy metabolism. Mitochondria are organelles wrapped by a double membrane, with the inner membrane forming cristae, which increase the surface area of the mitochondrial membrane greatly. As biofilms are targets of electromagnetic radiation [41], it can be inferred that the structural characteristics of mitochondria determine its high sensitivity to MW radiation-induced injury.

There are multiple possible ways through which MW radiation may structurally damage the mitochondrial membrane. First, MW radiation has the ability to enhance molecular rotation and vibration and to increase the collision frequency between molecules, leading to the breaking of chemical bonds and thus, damage to the mitochondrial membrane structure [42]. Second, MW radiation leads to a significant increase in intracellular reactive oxidative species (ROS) and the disorder of antioxidant enzymes, causing oxidative modification of biological macromolecules and mitochondrial damage [22,43-46]. Third, MW radiation causes intracellular $\mathrm{Ca}^{2+}$ overload and induces mitochondrial membrane injury through the activation of phospholipases and proteases [47-49].

\section{Apoptotic death of neural cells}

During the process of MW radiation-induced brain damage, apoptosis is one of the final outcomes of damaged cells. Blocking apoptosis to relieve the effect of MW radiation on the nervous system and to find new targets for prevention and treatment is of great value.

MW radiation induces neural cell apoptosis via the classical mitochondria-dependent caspase-3 pathway. Zuo et al. [50] exposed PC12-derived neuron-like cells and Wistar rats to $2.856 \mathrm{GHz}$ for $5 \mathrm{~min}$ and $15 \mathrm{~min}$, respectively, at an average power density of $30 \mathrm{~mW} / \mathrm{cm}^{2}$. The results showed chromatin condensation and apoptotic body formation in neural cells $6 \mathrm{~h}$ after MW exposure. Moreover, the mitochondrial membrane potential (MMP) decreased, and DNA fragmentation increased, leading to an increase in the percentage of apoptotic cells. Furthermore, the ratio of $\mathrm{Bax} / \mathrm{Bcl}-2$ and the expression of cytochrome c, cleaved caspase- 3 and PARP all increased. Kesari et al. [43] exposed 45-day-old male Wistar rats for $2 \mathrm{~h}$ a day for $60 \mathrm{~d}$ by mobile phone to investigate the effect of $3 \mathrm{G}$ cell phone exposure. The results showed that MW radiation emitted from the $3 G$ mobile phone significantly induced DNA strand breaks in the brain. Meanwhile, significant increases in micronuclei, caspase- 3 and apoptosis were also observed in the exposed group. Mitochondrial dysfunction-mediated cytochrome $\mathrm{c}$ release and the subsequent activation of caspases were found, which were involved in the process of radiation-induced apoptotic cell death.

\section{Oxidative stress}

MW radiation activates the NADH oxidase-mediated increase in ROS, and in turn, excessive ROS damages the mitochondrial electron transport chain, which is the main source of ROS, ultimately forming a vicious cycle and aggravating the disturbance in brain energy metabolism [13,51-54]. Deshmukh et al. [22] subjected Fischer344 rats to MW exposure (frequency of $900 \mathrm{MHz}$; SAR of $\left.8.4738 \times 10^{-5} \mathrm{~W} / \mathrm{kg}\right)$ in a gigahertz transverse electromagnetic cell (GTEM) for 30 days $(2 \mathrm{~h} / \mathrm{d}, 5 \mathrm{~d} /$ week). The results showed a significant increase in OS, as evidenced by the increase in levels of MDA (a marker of lipid peroxidation), protein carbonyl (a marker of protein oxidation) and unaltered glutathione (GSH) content in the blood. Thus, the study demonstrated that low-level MW radiation was capable of leading to OS. Kesari et al. [44] exposed 35-day old Wistar rats to a mobile phone for $2 \mathrm{~h}$ per day for a duration of $45 \mathrm{~d}$, where the SAR was $0.9 \mathrm{~W} / \mathrm{kg}$. The results indicated a significant increase in the level of ROS, a significant decrease in the levels of glutathione peroxidase (GPx) and superoxide dismutase (SOD), and an increase in catalase (CAT) activity. In addition, it is reported that inhibiting OS and removing ROS had a large therapeutic effect on MW radiationinduced brain damage $[55,56]$. Taken together, excessive ROS plays an important role during the process of MW radiation-induced injury to brain energy metabolism.

Excessive ROS is detrimental to brain energy metabolism. First, excessive levels of ROS-induced DNA breakage (nuclear and mitochondrial DNA) may be one of the key reasons for MW radiation-induced brain energy metabolism disorders [43,44,57-59]. Kesari et al. [43] had 45-dayold male Wistar rats exposed for $2 \mathrm{~h}$ a day for $60 \mathrm{~d}$ to a mobile phone and found that the ROS content showed a positive linear correlation with DNA damage. Another study showed that pretreatment with radical scavengers was capable of blocking MW radiation-induced DNA damage [59]. Second, excessive levels of ROS were closely related to neural cell apoptosis, as previously described $[43,44]$. Third, as a second messenger, increased ROSinduced excessive activation of one or more signaling pathways is believed to play a more important role in cell damage rather than in oxidative modification $[60,61]$. The role of ROS in MW radiation-induced brain damage needs to be further explored.

\section{$\mathrm{Ca}^{2+}$ overload}

Under normal circumstances, the extracellular free $\mathrm{Ca}^{2+}$ concentration is much higher than the intracellular concentration, and more than $90 \%$ of intracellular $\mathrm{Ca}^{2+}$ is stored in the endoplasmic reticulum and mitochondria. Therefore, a slight influx of $\mathrm{Ca}^{2+}$ is able to create a sharp rise in the concentration of cytoplasmic $\mathrm{Ca}^{2+}$ and trigger a series of physiological responses. 
Increased cytoplasmic $\mathrm{Ca}^{2+}$ exists during the process of MW radiation-induced brain damage. Yang et al. [47] exposed primary cultures of hippocampal neurons of rats to MW radiation for $5 \mathrm{~min}$ at an average power density of $10 \mathrm{~mW} / \mathrm{cm}^{2}$. The results showed a significant increase in cytoplasmic $\mathrm{Ca}^{2+}$ immediately after radiation. Lu et al. [48] exposed primary cultures of glial cells to $2450 \mathrm{MHz}$ for $2 \mathrm{~h} / \mathrm{d}$ for $3 \mathrm{~d}$ at an average power density of $4 \mathrm{~mW} / \mathrm{cm}^{2}$. An increased intracellular free $\mathrm{Ca}^{2+}$ was also found.

$\mathrm{Ca}^{2+}$ overload leads to brain energy metabolism disorders. Excessive activation of the mitochondrial permeability transition pore (mPTP), caused by $\mathrm{Ca}^{2+}$ overload, may be one important reason. Studies have reported that $\mathrm{Ca}^{2+}$ overload-induced activation of mPTP results in mitochondrial swelling and fragmentation [62,63]. In addition, when MPTP is activated excessively, the mitochondrial membrane permeability increases, MMP disappears, the respiratory chain is uncoupled from OXPHOS and ATP synthesis ceases [64,65]. Additionally, $\mathrm{Ca}^{2+}$ is an important intracellular second messenger that is able to activate a variety of signaling molecules such as PKC, AC and cAMP-PDE. The role played by $\mathrm{Ca}^{2+}$ during $\mathrm{MW}$ radiation-induced mitochondrial injury deserves more in-depth research.

\section{Impaired mitochondrial DNA}

Mitochondrial DNA (mtDNA) encodes 13 subunits of the respiratory chain complex and 22 tRNA and 2 rRNA of mitochondria, and is of the utmost importance to OXPHOS and ATP synthesis. Mitochondrial transcription factor A (mtTFA), a key factor encoded by nuclear genes involved in the regulation of mtDNA, plays important roles in the integrity, self-replication and repair of mtDNA after being transported from the cytoplasm to the mitochondria [66].

MW radiation can break mtDNA or change the expression of mtDNA, resulting in decreased ATP production. First, mtDNA, with the structure of a double helix ring, lacks the protection of protein binding and repair systems and is much more susceptible to external stimuli, such as MW radiation, than nuclear DNA is. MW radiation is capable of breaking nuclear DNA strands [43,44,57-59]. In addition, ROS has the ability to induce mtDNA mutations and create barriers in OXPHOS and ATP generation [67]. However, the effects of MW radiation-induced mtDNA damage on brain energy metabolism still require further study. Second, mtTFA needs to be properly transferred from the cytoplasm to the mitochondria to function, which leads to mitochondrial dysfunction when this process is disturbed by MW radiation. Xie et al. [27] exposed male Wistar rats to MW radiation $\left(30 \mathrm{~mW} / \mathrm{cm}^{2}\right.$, duration: $\left.1 \mathrm{~h}\right)$. The expression of mtTFA mRNA in the rat hippocampus and cerebral cortex increased, responding to the reduced ATP content within a possible negative feedback regulation. $\mathrm{Xu}$ et al. [68] exposed primary cultures of cortical neurons of neonatal rats to MW radiation (frequency and power density unknown). The expression of mtTFA mRNA and protein increased, but new mtTFA did not inhibit the impact of MW radiation on energy metabolism. In another study, these authors confirmed the inhibitory effect of MW radiation on the transport of mtTFA from the cytoplasm into the mitochondria by using isotopelabeling technique, which may be the primary reason for the MW radiation-induced ATP decrease [69].

\section{Signaling pathways involved}

There are many signaling pathways involved in the process of MW radiation-induced mitochondrial dysfunction, including the phosphatidylinositol 3-kinase (PI3K) pathway and the mitogen-associated protein kinase (MAPK) pathway, which are adaptive responses of cells that regulate cellular functions and promote their survival.

\section{PI3K/Akt pathway}

There is enough evidence that the PI3K/Akt pathway, an anti-apoptotic prosurvival kinase signaling cascade, plays a pivotal role in cellular survival $[70,71]$. Hypoxia inducible factor- $1 \alpha$ (HIF-1 $\alpha$ ), a key physiological sensor of oxygen level in most mammalian cells, plays an important role in cellular survival, glucose metabolism and transport and metabolic adaptation by regulating the expression of its target genes [72-75]. In addition, it has been shown that activation of HIF- $1 \alpha$ by the PI3K/Akt/ mTOR signaling pathway plays an important role in neuroprotection [76,77].

Great importance has been attached to the PI3K/Akt signaling pathway during the process of MW radiationinduced brain damage, and the activation of HIF- $1 \alpha$, a key target molecule of PI3K/Akt pathway, is capable of restoring the impaired mitochondrial energy metabolism caused by MW radiation to a certain extent. Wang et al. [78] exposed rats to acute MW radiation for $5 \mathrm{~min}$ at average power densities of 30 and $100 \mathrm{~mW} / \mathrm{cm}^{2}$, respectively. The expression of HIF- $1 \alpha$ mRNA and protein in the rat hippocampus and cerebral cortex increased significantly at $6 \mathrm{~h}$ to $1 \mathrm{~d}$ after radiation. Another study had male Wistar rats exposed to pulsed MW radiation for $30 \mathrm{~d}(6 \mathrm{~min} / \mathrm{d}, 5 \mathrm{~d} /$ week $)$ at average power densities of $2.5,5$ and $10 \mathrm{~mW} / \mathrm{cm}^{2}$, respectively. The expression of HIF- $1 \alpha$ mRNA and protein in the rat hippocampal neurons increased at $14 \mathrm{~d}$ to 1 month after radiation in the 2.5 and $5 \mathrm{~mW} / \mathrm{cm}^{2}$ groups, but decreased in the $10 \mathrm{~mW} / \mathrm{cm}^{2}$ group [79]. Thus, HIF-1 $\alpha$ upregulation occurs after both single acute and long-term MW radiation. However, it is not clear whether the activated HIF- $1 \alpha$ is 
helpful to the cells impaired by MW radiation. Zhao et al. [24] exposed PC12-derived neural-like cells to MW radiation of $30 \mathrm{~mW} / \mathrm{cm}^{2}$ for $5 \mathrm{~min}$. HIF-1 $\alpha$ overexpression protected mitochondria from injury by increasing ATP and MMP levels, while HIF- $1 \alpha$ silencing promoted MWinduced mitochondrial damage. PI3K signaling activation was required for the MW-induced HIF-1 $\alpha$ activation and protective response. Although HIF-1 $\alpha$ represents a promising therapeutic target for MW radiation injury, how HIF- $1 \alpha$ is regulated and what its effective targets in the mitochondria may be remain unknown.

\section{MAPK pathway}

MAPK, which is composed of different gene products terminating in a variety of transcription factors involved in survival, proliferation and cell death, depending on the strength of the stimulus, regulates the balance between cell survival/differentiation and cell death/apoptosis [80]. The three subfamilies of MAPK include extracellular regulated protein kinase (ERK), c-jun N-terminal kinase/ stress-activated protein kinase (JNK/SAPK) and p38MAPK.

ERK signaling-mediated upregulation of HIF- $1 \alpha$ protects from mitochondrial dysfunction caused by $\mathrm{MW}$ radiation. Zhao et al. [24] exposed PC12-derived neurallike cells to $\mathrm{MW}$ radiation of $30 \mathrm{~mW} / \mathrm{cm}^{2}$ for $5 \mathrm{~min}$. Inhibition of $\mathrm{p}$-Erk1/2 promoted a MW-induced decrease of ATP and MMP levels and induced a decreased expression of HIF-1 $\alpha$, demonstrating that ERK signaling was involved in the protective mechanism against MWinduced mitochondrial injury.

p38MAPK, known as cell death MAPK signaling, is involved in MW radiation-induced neural cell apoptosis. p38MAPK induces apoptosis by regulating the conformational changes and subsequent oligomerization of Bax, the dissipation of MMP and the cytochrome $\mathrm{c}$ release from mitochondria [81]. Kesari et al. [43] exposed 45day-old male Wistar rats for $2 \mathrm{~h}$ a day for $60 \mathrm{~d}$ to a mobile phone to investigate the effect of $3 \mathrm{G}$ cell phone exposure. They found that the $3 \mathrm{G}$ mobile radiation induced apoptosis in the brain by activation of p38MAPK, the pathway of principal stress response.

\section{Conclusion}

To date, the damaging effects of MW radiation on mitochondrial structure and function have been recognized, and studies at the cellular and molecular level on the related mechanisms have also made advances, enabling a number of potential molecular targets for the prevention and treatment of MW radiation to be proposed.

The following issues are present in this sphere of research: (a) MW radiation-induced disturbance of brain energy metabolism involves numerous parameters, such as the dose, time and frequency, which need to be explored further; (b) the biological effects of $\mathrm{MW}$ radiation are widespread, involving varieties of signaling pathways, and the present review is confined to investigating single signaling pathways and unable to analyze the effects of cross-talk between the various signaling pathways; (c) there are no specific markers for evaluating MW radiation damage effects and no effective molecular targets for the prevention and treatment of their injuries; (d) the after effects of MW radiation-induced mitochondrial damage are still unclear, and its correlation with mitochondria-related neurodegenerative diseases, such as Alzheimer's disease, requires further study. The lack of identical standards among different laboratories creates a barrier for further development and exchange of information.

Taken together, this review on the effects of MW radiation on brain energy metabolism and the associated regulation mechanisms, molecular markers, drug targets and prevention measures shows the need for continued research efforts in this area.

\section{Abbreviations}

ATP: Adenosine triphosphate; CAT: Catalase; CoQ: Coenzyme Q; COX: Cytochrome c oxidase; ERK: Extracellular regulated protein kinase; FADH2: Reduced flavin adenine dinucleotide; GPx: Glutathione peroxidase; GSH: Glutathione; GTEM: Gigahertz transverse electromagnetic cell; HIF-1a: Hypoxia inducible factor-1a; HPM: High power microwave; JNK: cjun N-terminal kinase; MAPK: Mitogen-associated protein kinase; MMP: Mitochondria membrane potential; mPTP: Mitochondrial permeability transition pore; mtDNA: Mitochondrial DNA; mtTFA: Mitochondrial transcription factor A; MW: Microwave; NADH: Reduced nicotinamide adenine dinucleotide; OS: Oxidative stress; OXPHOS: Oxidative phosphorylation; PI3K: Phosphatidylinositol 3-kinase; ROS: Reactive oxidative species; SAPK: Stress-activated protein kinase; SAR: Specific absorption rate; SDH: Succinate dehydrogenase; SOD: Superoxide dismutase.

\section{Competing interests}

The authors declare that they have no competing interests.

\section{Authors' contributions}

$\mathrm{YH}$ participated in the design and collected and analyzed the data. LZ and RP conceived of the review and helped to draft the manuscript. All authors read and approved the final manuscript.

\section{Acknowledgements}

This work was supported by the National Natural Science Foundation of China (No. 81372926).

Received: 21 October 2014 Accepted: 29 January 2015

Published online: 17 February 2015

\section{References}

1. Röösli M, Rapp R, Braun-Fahrländer C. Radio and microwave frequency radiation and health-an analysis of the literature. Gesundheitswesen. 2003;65:378-92.

2. Adair ER, Black DR. Thermoregulatory responses to RF energy absorption. Bioelectromagnetics. 2003;24:S17-38.

3. Black DR, Heynick LN. Radiofrequency (RF) effects on blood cells, cardiac, endocrine, and immunological functions. Bioelectromagnetics. 2003;24: S187-95.

4. Cao GF, Tong J, Wang J, Liu Q, Jin YL. Study on Effect of Weak Radio-frequency Electomagnetic Field on Neurobehavioral of Human and Mice. Ind Hlth Occup Dis. 2004;30:135-7. 
5. Zhao L, Peng RY, Wang SM, Wang LF, Gao YB, Dong J, et al. Relationship between cognition function and hippocampus structure after long-term microwave exposure. Biomed Environ Sci. 2012;25:182-8.

6. Hu SH, Peng RY, Wang SM, Gao YB, Dong J, Xu XP, et al. Ptotective effects of Kang Fu Ling on brian injury induced by microwave radiation in rats. Chin J Stereol Image Anal. 2013;18:48-54.

7. Ren JH, Peng RY, Zhang J, Li J, Gao YB, Wang SM, et al. Prevention effects of AduoLa Fuzhenglin on brian injury induced by microwave radiation in rats. Chin J Radio Med Prot. 2011;31:190-3.

8. LV SJ, Tian ZJ, Jiang YX, Wang C, Lu XJ, Pan WG. Effects of high power pulsed microwave radiation on brain structure and function in rats. Chin J Public Health. 2009;25:177-8.

9. Zhong XH, Xu JJ, Liu HM, Jiang YX, Lu XJ, Lv S. Morphological changes of heart and liver induced by high power microwave HPM radiation in rats. Chin J Public Health. 2010;26:1559-60.

10. Esmekaya MA, Aytekin E, Ozgur E, Güler G, Ergun MA, Omeroğlu S, et al. Mutagenic and morphologic impacts of $1.8 \mathrm{GHz}$ radiofrequency radiation on human peripheral blood lymphocytes (hPBLs) and possible protective role of pre-treatment with Ginkgo biloba (EGb 761). Sci Total Environ. 2011;410-411:59-64

11. Ma Q, Du L, Cui YF, Guo Y, Sun R, Dong B, et al. Effects of $5 \mathrm{~mW} / \mathrm{cm}^{2}$ microwave irradiation with different pulse widths on human $\mathrm{AHH}-1 \mathrm{~T}$ lymphocytes. Med J Chin PLA. 2010;35:1311-4.

12. Hu HX, Fang H, Luo SB, Dong J, Wei LZ. Effects of microwave radiaiton on the ultrastructure of sperm head and tail of radar-operators. Chin J Androl. 2010;24:33-5.

13. Shahin S, Singh VP, Shukla RK, Dhawan A, Gangwar RK, Singh SP, et al. $2.45 \mathrm{GHz}$ microwave irradiation-induced oxidative stress affects implantation or pregnancy in mice, Mus musculus. Appl Biochem Biotechnol. 2013;169:1727-51.

14. Yao BW, Peng RY, Wang SM, Gao YB, Dong J, Xu XP, et al. Preventive and therapeutic effects of a traditional Chinese medicine "Kang Fu Ling" on the sperm injury in rats induced. Chin J Stereol Image Anal. 2012;17:149-55.

15. Guo S, Wang $X, X u$ J, Lei J, Sun $K$, Jiang $X$, et al. Effect of microwave radiation on the rat hematopoietic system. J Hyg Res. 2011;40:223-6.

16. Balduini W, Carloni S, Buonocore G. Autophagy in hypoxia-ischemia induced brain injury. J Matern Fetal Neonatal Med. 2012;1:30-4.

17. Greene-Schloesser D, Robbins ME, Peiffer AM, Shaw EG, Wheeler KT, Chan MD. Radiation-induced brain injury: A review. Front Oncol. 2012;2:73.

18. Wang H, Peng R, Zhou H, Wang S, Gao Y, Wang L, et al. Impairment of long-term potentiation induction is essential for the disruption of spatial memory after microwave exposure. Int J Radiat Biol. 2013;89:1100-7.

19. Xu S, Ning W, Xu Z, Zhou S, Chiang H, Luo J. Chronic exposure to GSM $1800 \mathrm{MHz}$ microwaves reduces excitatory synaptic activity in cultured hippocampal neurons. Neurosci Lett. 2006:398:253-7.

20. Jauchem JR. A literature review of medical side effects from radio-frequency energy in the human environment: involving cancer, tumors, and problems of the central nervous system. J Microw Power Electromagn Energy. 2003;38:103-23.

21. Dong J, Peng RY, Wang SM, Gao YB, Wang LF, Zhao L, et al. Effects on abilities of learning and memory and structural changes of brain in rats induced by microwave radiation under different conditions. Mil Med Sci. 2011;35:347-50.

22. Deshmukh PS, Banerjee BD, Abegaonkar MP, Megha K, Ahmed RS, Tripathi $A K$, et al. Effect of low level microwave radiation exposure on cognitive function and oxidative stress in rats. Indian J Biochem Biophys. 2013:50:114-9.

23. Ma D, Peng RY, Gao YB, Wang SM, Zhao L, Wang SX, et al. Effects of microwave radiation on structure and energy metabolism in rat hippocampus. Chin J Stereol Image Anal. 2010;15:420-4.

24. Zhao L, Yang YF, Gao YB, Wang SM, Wang LF, Zuo HY, et al. Upregulation of HIF-1a Via Activation of ERK and PI3K Pathway Mediated Protective Response to Microwave-Induced Mitochondrial Injury in Neuron-Like Cells. Mol Neurobiol. 2014;50:1024-34.

25. Zhao L, Peng RY, Gao YB, Wang SM, Wang LF, Dong J, et al. Mitchondria morphologic changes and metabolic effects of rat hippocampus after microwave irradiation. Chin J Radiol Med Prot. 2007;27:602-4.

26. Wang LF, Li X, Peng RY, Gao YB, Zhao L, Wang SM, et al. A metabolomic approach to screening urinary metabolites upon microwave exposure in monkeys. Mil Med Sci. 2011;35:369-74. 378.

27. Xie $Y$, Jiang HH, Gong XF, Zhuang GB, Yu JH, Yu ZP. Effect of microwave irradiation on neurocyte mitochondrial ultrastructure and mtTFA mRNA expression in rats cerebral cortex and hippocampus. Chin J Ind Hyg Occup Dis. 2004:22:28-31.

28. Sanders AP, Joines WT. The effects of hyperthermia and hyperthermia plus microwaves on rat brain energy metabolism. Bioelectromagnetics. 1984;5:63-70.

29. Wang LF, Peng RY, Hu XJ, Gao YB, Ma JJ, Wang X, et al. Studies on the influence of high power microwave radiation on energy metabolism of brian in rats. Chin J Radiol Health. 2006;15:269-71.

30. Correia SC, Santos RX, Perry G, Zhu X, Moreira PI, Smith MA. Mitochondria: the missing link between preconditioning and neuroprotection. J Alzheimers Dis. 2010;20:S475-85.

31. Luques L, Shoham S, Weinstock M. Chronic brain cytochrome oxidase inhibition selectively alters hippocampal cholinergic innervation and impairs memory: prevention by ladostigil. Exp Neurol. 2007;206:209-19.

32. Mattson MP, Gleichmann M, Cheng A. Mitochondria in neuroplasticity and neurological disorders. Neuron. 2008:60:748-66.

33. Wang Q, Cao ZJ, Bai XT. Effect of microwave electromagnetic fields on activity of energy metabolism cytochrome oxidase in cerebral cortical neurons of postnatal rats. J Environ Health. 2006;22:329-31.

34. Xiong L, Peng RY, Gao YB, Wang SM, Wang LF, Dong J, et al. Effects of AduoLa Fuzhenglin on changes of cytochrome c oxidase in rats hippocampus after microwave exposure. Mil Med Sci. 2011;35:333-7.

35. Zhao L, Peng RY, Gao YB, Wang SM, Ma JJ, Wang LF, et al. Screening for differentially expressed genes in rats' hippocampus after microwave radiation. Chin J Public Health. 2007;23:1153-5.

36. Ongwijitwat $\mathrm{S}$, Wong-Riley MT. Is nuclear respiratory factor 2 a master transcriptional coordinator for all ten nuclear-encoded cytochrome c oxidase subunits in neurons? Gene. 2005;360:65-77.

37. Chandrasekaran K, Hatanpää K, Rapoport SI, Brady DR. Decreased expression of nuclear and mitochondrial DNA-encoded genes of oxidative phosphorylation in association neocortex in Alzheimer disease. Brain Res Mol Brain Res. 1997:44:99-104.

38. Zhao L, Peng RY, Gao YB, Wang SM, Wang XM, Xu XP, et al. The changes of the COX gene expression in mitochondria in hippocampus of rats after exposure to microwave radiation. Chin J Phys Med Rehabil. 2009;30:31-3.

39. Xie $Y$, Jiang $H H$, Gong XF, Zhang GB, Lu B, Xu Q, et al. Effects of microwave irradiation on mitochondrial cytochrome $C$ oxidase subunits mRNA in rat brain. Acta Academiae Medicinae Militaris Tertlae. 2003;25:987-9.

40. Ellis CE, Murphy EJ, Mitchell DC, Golovko MY, Scaglia F, Barcelo-Coblijn GC, et al. Mitochondrial lipid abnormality and electron transport chain impairment in mice lacking alpha-synuclein. Mol Cell Biol. 2005;25:10190-201.

41. Caubet R, Pedarros-Caubet F, Chu M, Freye E, De Belem RM, Moreau JM, et al. A radio frequency electric current enhances antibiotic efficacy against bacterial biofilms. Antimicrob Agents Chemother. 2004;48:4662-4.

42. Wang $Y$, Sun HT, Wang BH, Zhang D. A study on thermal efficiency and non-thermal efficiency of microwave. Liaoning Chem Ind. 2006:35:167-9.

43. Kesari KK, Meena R, Nirala J, Kumar J, Verma HN. Effect of 3G Cell Phone Exposure with Computer Controlled 2-D Stepper Motor on Non-thermal Activation of the hsp27/p38MAPK Stress Pathway in Rat Brain. Cell Biochem Biophys. 2014;68:347-58.

44. Kesari KK, Kumar S, Behari J. 900-MHz microwave radiation promotes oxidation in rat brain. Electromagn Biol Med. 2011;30:219-34.

45. Chen YM, Chen JY, Liu XH, Luo WJ, Wang Q, Xu H, et al. Effects of complementary zinc on antioxidase in brian of rats irradiated by microwave. J Fourth Mil Med Univ. 2005;26:444-6

46. Wang RY, Yang CL, Luo LH, Zhang JQ, Mu HL, Du P, et al. Oxidative stress effect of microwave radiation on mice brian. J Prev Med Chin PLA. 2013;31:292-4

47. Yang R, Peng RY, Gao YB, Wang SM, Hu WH, Xu XP, et al. The effect of microwaves on hippocampal neurons in vitro and its mechanism. Chin J Phys Med Rehabil. 2006;28:670-3.

48. Lu MX, Nie JH, Zhu JQ, Qian C, Wang GH, Tong J. Biological effects of $2450 \mathrm{MHz}$ microwave combined with $\mathrm{\gamma}$-rays on rat cultured gliacytes. J Radiat Res Raidat Process. 2010;28:172-6.

49. Whiteman M, Armstrong JS, Cheung NS, Siau JL, Rose P, Schantz JT, et al. Peroxynitrite mediates calcium-dependent mitochondrial dysfunction and cell death via activation of calpains. FASEB J. 2004:18:1395-7.

50. Zuo HY, Lin T, Wang DW, Peng RY, Wang SM, Gao YB, et al. Neural cell apoptosis induced by microwave exposure through mitochondria-dependent caspase-3 pathway. Int J Med Sci. 2014;11:426-35.

51. Campisi A, Gulino M, Acquaviva R, Bellia P, Raciti G, Grasso R, et al. Reactive oxygen species levels and DNA fragmentation on astrocytes in primary 
culture after acute exposure to low intensity microwave electromagnetic field. Neurosci Lett. 2010;473:52-5.

52. Sokolovic D, Djindjic B, Nikolic J, Bjelakovic G, Pavlovic D, Kocic G, et al. Melatonin reduces oxidative stress induced by chronic exposure of microwave radiation from mobile phones in rat brain. J Radiat Res. 2008:49:579-86.

53. Ammari M, Lecomte A, Sakly M, Abdelmelek H, De-Seze R. Exposure to GSM $900 \mathrm{MHz}$ electromagnetic fields affects cerebral cytochrome c oxidase activity. Toxicology. 2008;250:70-4.

54. Friedman J, Kraus S, Hauptman Y, Schiff Y, Seger R. Mechanism of short-term ERK activation by electromagnetic fields at mobile phone frequencies. Biochem J. 2007:405:559-68.

55. Tian ZJ, Shen N, Lv SJ, Wang C, Jiang YX, Luo J. The effects of Polysaccharides from Auricularia auricular on SOD in serum and lipid peroxidation in liver homogenate of rat by high power microwave radiation. Lishizhen Med Materia Medica Res. 2009;20:3011-3.

56. Wu ZY, Xu TH, Peng RY, Gao YB, Wang SM, Ma JJ, et al. The protective effect of GSH on injury to brian energy metabolism induced by HPM in rats. Chin J Stereol Image Anal. 2006;11:127-30.

57. Paulraj R, Behari J. Single strand DNA breaks in rat brain cells exposed to microwave radiation. Mutat Res. 2006;596:76-80.

58. Lai H, Singh NP. Magnetic-field-induced DNA strand breaks in brain cells of the rat. Environ Health Perspect. 2004;112:687-94.

59. Meena R, Kumari K, Kumar J, Rajamani P, Verma H, Kesari KK. Therapeutic approaches of melatonin in microwave radiations-induced oxidative stress-mediated toxicity on male fertility pattern of Wistar rats. Electromagn Biol Med. 2014:33:81-91.

60. Johnson GL, Lapadat R. Mitogen-activated protein kinase pathways mediated by ERK, JNK, and p38 protein kinases. Science. 2002;298:1911-2.

61. Maher P, Schubert D. Signaling by reactive oxygen species in the nervous system. Cell Mol Life Sci. 2000;57:1287-305.

62. Petronilli V, Penzo D, Scorrano L, Bernardi P, Di Lisa F. The mitochondrial permeability transition, release of cytochrome $\mathrm{c}$ and cell death. Correlation with the duration of pore openings in situ. J Biol Chem. 2001;276:12030-4.

63. Halestrap AP, Doran E, Gillespie JP, O'toole A. Mitochondria and cell death. Biochem Soc Trans. 2000;28:170-7.

64. Vaux DL. CED-4-the third horseman of apoptosis. Cell. 1997;90:389-90.

65. Golstein P. Controlling cell death. Science. 1997;275:1081-2.

66. Kang $D$, Hamasaki N. Mitochondrial transcription factor $A$ in the maintenance of mitochondrial DNA. Ann N Y Acad Sci. 2005;1042:101-8.

67. $\mathrm{Li} \mathrm{HX,} \mathrm{Li} \mathrm{CH.} \mathrm{Apoptosis} \mathrm{gene} \mathrm{expression} \mathrm{and} \mathrm{their} \mathrm{relationship} \mathrm{to} \mathrm{mtDNA}$ mutation in tumor tissues of gynecologic oncology patients. Chin J Birth Health Hered. 2003;1 1:34-6.

68. Xu SC, Zhang L, Yu ZP, Zhong M. Effects of microwave exposure on Tfam expression in neurons and the relationship with energy metabolism disturbance. J Radiat Res Radiat Process. 2008;26:305-8.

69. Xu SC, Yu ZP, Wu J, Pei LP, Luo X, Chen CH, et al. Inhibitory effect of microwave exposure on the import of mitochondrial transcription factor $\mathrm{A}$ (Tfam). J Radiat Res Radiat Process. 2009;27:173-6.

70. Sheppard K, Kinross KM, Solomon B, Pearson RB, Phillips WA. Targeting PI3 kinase/AKT/mTOR signaling in cancer. Crit Rev Oncog. 2012;17:69-95.

71. Prasad SS, Russell M, Nowakowska M. Neuroprotection induced in vitro by ischemic preconditioning and postconditioning: modulation of apoptosis and PI3K-Akt pathways. J Mol Neurosci. 2011;43:428-42.

72. Fan X, Heijnen CJ, Van Der Kooij MA, Groenendaal F, Van Bel F. The role and regulation of hypoxia-inducible factor-1 a expression in brain development and neonatal hypoxic-ischemic brain injury. Brain Res Rev. 2009;62:99-108.

73. Hu Q, Wu C, Chen J, Yan F, Li J, Chen G. The relationship between hypoxia-inducible factor-1 a expression and apoptosis in early brain injury after subarachnoid hemorrhage. J Zhejiang University Med Sci. 2014;43:58-65.

74. Singh N, Sharma G, Mishra V, Raghubir R. Hypoxia inducible factor-1: Its potential role in cerebral ischemia. Cell Mol Neurobiol. 2012;32:491-507.

75. Li Y, Xia ZL, Chen LB. HIF-1-alpha and survivin involved in the anti-apoptotic effect of 2ME2 after global ischemia in rats. Neurol Res. 2011;33:583-92.

76. Ye Z, Guo Q, Xia P, Wang N, Wang E, Yuan Y. Sevoflurane postconditioning involves an up-regulation of HIF-1a and HO-1 expression via PI3K/Akt pathway in a rat model of focal cerebral ischemia. Brain Res. 2012;1463:63-74.

77. Xu J, Peng Z, Li R, Dou T, Xu W, Gu G, et al. Normoxic induction of cerebral HIF-1alpha by acetazolamide in rats: role of acidosis. Neurosci Lett. 2009:451:274-8
78. Wang $X$, Hu XJ, Peng RY, Wang SM, Gao YB, Wang LF, et al. Expression and significance of hypoxia inducible factor-1 alpha in rat brain after HPM exposure. Chin J Public Health. 2007;23:1161-3.

79. Zhao L, Peng RY, Gao YB, Wang SM, Wang LF, Dong J, et al. Activation of HIF-1a/ERK pathway regulates the injury of neuron mitochondria in hippocampus induced by long-term microwave exposure. SCIENTIA SINICA Vitae. 2011;41:945-50.

80. Bickler PE, Donohoe PH. Adaptive responses of vertebrate neurons to hypoxia. J Exp Biol. 2002;205:3579-86.

81. Choi SY, Kim MJ, Kang CM, Bae S, Cho CK, Soh JW, et al. Activation of Bak and Bax through c-abl-protein kinase Cdelta-p38 MAPK signaling in response to ionizing radiation in human non-small cell lung cancer cells. J Biol Chem. 2006;281:7049-59.

\section{Submit your next manuscript to BioMed Central and take full advantage of:}

- Convenient online submission

- Thorough peer review

- No space constraints or color figure charges

- Immediate publication on acceptance

- Inclusion in PubMed, CAS, Scopus and Google Scholar

- Research which is freely available for redistribution 